\title{
Seroprevalence of Dirofilaria immitis in Cats from Liaoning Province, Northeastern China
}

\author{
Honglie Hou ${ }^{1,2, \dagger}$, Lili Cao ${ }^{1,3, \dagger}$, Wenzhi Ren ${ }^{4, \dagger}$, Dansheng Wang ${ }^{2}$, He Ding ${ }^{1}$, Juan You $^{5}$, Xinhua Yao ${ }^{3}$, Hang Dong ${ }^{3}$, \\ Yanbing Guo ${ }^{3}$, Shuxian Yuan ${ }^{3}$, Xichen Zhang', Pengtao Gong ${ }^{1, *}$ \\ ${ }^{1}$ Key Laboratory of Zoonosis, Ministry of Education, College of Veterinary Medicine, Jilin University, Changchun, 130062, China; ${ }^{2}$ School of \\ Agriculture Eastern Liaoning University, Dandong 118003, China; ${ }^{3}$ Jilin Academy of Animal Husbandry and Veterinary Medicine, Changchun, Jilin \\ 130062, China; ${ }^{4}$ College of Animal Sciences, Jilin University, Changchun, Jilin Province 130062, China; ${ }^{5}$ School of Medicine Eastern Liaoning \\ University, Dandong 118003, China
}

\begin{abstract}
The present study was performed to investigate the seroprevalence and risk factors for Dirofilaria immitis infection in cats from Liaoning province, northeastern China. From October 2014 to September 2016, sera of 651 cats, including 364 domestic cats and 287 feral cats (332 females and 319 males) were assessed. They were tested for the presence of $D$. immitis antigen using SNAP Heartworm RT test kit. In this population, the average prevalence was $4.5 \%$. Age and rearing conditions (feral or domestic) were found to be associated with the prevalence of $D$. immitis. The prevalence was significantly higher in feral cats compared with domestic cats $(8.4 \%$ vs $1.4 \%, P<0.01)$. There was no significant difference between males and females $(4.7 \%$ vs $4.2 \%, P>0.05)$, but older cats ( $\geq 3$ years old) showed a statistically higher prevalence compared with younger cats ( $<3$ years old) in feral populations ( 16.8 vs $2.4 \%, P<0.01)$, while the difference between the age groups was not statistically significant in domestic cats $(2.4 \%$ vs $0.51 \%, P>0.05)$, all these results suggest that outdoor exposure time may be one of the most important factors for $D$. immitis prevalence in cats. Results reveal that $D$. immitis are prevalence in domestic and feral cats in northeastern China, which indicates that appropriate preventive measures should be taken to decrease the incidence of feline heartworm disease in Liaoning province, northeastern China.
\end{abstract}

Key words: Dirofilaria immitis, seroprevalence, cat, Liaoning province

Dirofilaria immitis, the etiologic agent of canine heartworm disease, is commonly found in the pulmonary artery and right ventricle of dogs and other animals. It could infect dogs, cats, and various wild mammals, with increased incidence in temperate and tropical areas [1]. The heartworm parasite is transmitted by various mosquito species, including Aedes, Anopheles, and Culex [2,3]. After mosquitoes feed on an infected microfilaremic reservoir host, the mosquitoes act as intermediate hosts, carrying infectious "larvae 3" (L3) stage larvae, which could be transmitted to a dog or a cat [4].

Although D. immitis is most commonly found in dogs and other canids, the importance of D. immitis in cats is an increasingly recognized problem, alluded to as early as 15 years ago [5]. In addition, the prevalence of heartworm disease in other

- Received 22 May 2016, revised 24 October 2017, accepted 25 November 2017.

*Corresponding author (gongpt@jlu.edu.cn)

${ }^{\dagger}$ These authors contributed equally to this paper.

(c) 2017, Korean Society for Parasitology and Tropical Medicine

This is an Open Access article distributed under the terms of the Creative Commons Attribution Non-Commercial License (http://creativecommons.org/licenses/by-nc/4.0) which permits unrestricted non-commercial use, distribution, and reproduction in any medium, provided the original work is properly cited. species has increased in the past 10 years, with the geographic range of heartworm infection also significantly increased in the canine and feline species [6]. D. immitis has been frequently detected in cats in many countries, including the United States [7], Canary Islands [8], Malaysia [9], Korea [10], Portugal [11], and Italy [12]. In China, several studies have reported the prevalence of D. immitis in dogs, $12.7 \%$ in Shenyang city and $24.0 \%$ in Dandong city, northeastern China [13,14], 13\% in Henan province and $31.2 \%$ in Xian city, central China $[15,16]$. The prevalence is $13.5 \%$ in southern China, such as Nanchang, Fuzhou, Guangzhou, Shenzhen, Nanning [17]. 61.3\% in Chongqing [18], the seoprevalences of $D$. immitis were also found in Beijing $(0.33 \%, 1 / 300)$ and Shanghai $(3.3 \%, 1 / 30)$ [19]. Moreover, the seroprevalence in Taipei city and mountain aboriginal districts were $13.8 \%$ and $12.1 \%$ in domestic dogs [20]. The occurrence of $D$. immitis suggested that the dog population in China is at potential risk for D. immitis.

However, there are very few published epidemiological data regarding feline heartworm prevalence in China. The prevalence of D. immitis in cats was 3.04\% in Gansu province, 
northwestern China [21], and 1.93\% in stray cats collected from Liaoning, Jilin, Heilongjiang, and Shandong province, eastern China [22], which is the only report to date. Therefore, it is very important to collect information on the prevalence of D. immitis in cats. The purpose of this study was to determine the seroprevalence of $D$. immitis in cats and analyze its related risk factors in Liaoning province, northeastern China.

Liaoning province is located in the northeastern of mainland China, covering an area of 148,000 $\mathrm{km}^{2}$ and a population of 43.91 million approximately. Its geographical position is at east longitude $118^{\circ} 53^{\prime}-125^{\circ} 46^{\prime}$ and at north latitude $38^{\circ}$ $43^{\prime}-43^{\circ} 26^{\prime}$. The area has a continental monsoon climate, winter is longer than other seasons, and summer is warm. The average annual temperature is $7-11^{\circ} \mathrm{C}$, with a mean annual rainfall of $600-1,100 \mathrm{~mm}$. There are 14 provincial cities distributed in Liaoning province, with the city of Shenyang as its capital (Fig.1). Nine cities including Shenyang $\left(41^{\circ} 8^{\prime} \mathrm{N}, 123^{\circ} 38^{\prime} \mathrm{E}\right)$, Dalian ( $\left.38^{\circ} 92^{\prime} \mathrm{N}, 121^{\circ} 62^{\prime} \mathrm{E}\right)$, Anshan ( $\left.41^{\circ} 1^{\prime} \mathrm{N}, 122^{\circ} 98^{\prime} \mathrm{E}\right)$, Benxi $\left(41^{\circ} 3^{\prime} \mathrm{N}, 123^{\circ} 73^{\prime} \mathrm{E}\right)$, Dandong $\left(40^{\circ} 13^{\prime} \mathrm{N}, 124^{\circ} 37^{\prime} \mathrm{E}\right)$, Jinzhou $\left(41^{\circ} 13^{\prime} \mathrm{N}, 121^{\circ} 15^{\prime} \mathrm{E}\right)$, Huludao $\left(40^{\circ} 77^{\prime} \mathrm{N}, 120^{\circ} 83^{\prime} \mathrm{E}\right)$, Chaoyang $\left(41^{\circ} 58^{\prime} \mathrm{N}, 120^{\circ} 42^{\prime} \mathrm{E}\right)$, and Fuxin $\left(42^{\circ} \mathrm{N}, 121^{\circ} 65^{\prime} \mathrm{E}\right)$, located in the northern, western, central, southern, and eastern parts of Liaoning province, were selected for sample collection for this study.

From October 2014 to September 2016, a total of 651 blood samples were collected, including 364 domestic cat samples (collected from pet owners) and 287 feral cat samples (collected from humane cat traps) from Shenyang (29 domestic and
53 feral), Dalian (24 domestic and 40 feral), Anshan (42 domestic and 19 feral), Benxi (48 domestic and 28 feral), Jinzhou (50 domestic and 17 feral), Huludao (39 domestic and 20 feral), Chaoyang (53 domestic and 25 feral), Fuxin (36 domestic and 17 feral) and Dandong (43 domestic and $68 \mathrm{fe}$ ral) in Liaoning province, northeastern China. All operations were handled in strict accordance with the Good Animal Practice requirements of the Animal Ethics Procedures and Guidelines of the People's Republic of China. This study was approved by the Animal Ethics Committee of Jilin University (IACUC approval no. 20140901). The domestic cats for sample collection were selected according to the following criteria. First, cats had never been moved outside of the study area according to the owners. Second, animals were more than 6 months old. Third, animals must have no past history or diagnosis of heartworm infection. Finally, owners were willing to participate in this survey and authorized it. Meanwhile, the feral cats were collected from humane cat traps as follows. Humane cat traps containing food and water were set in shaded areas and checked the next morning. Trapped cats were transported to the Small Animal Hospital at Jilin University or Eastern Liaoning University. Then, they were anaesthetized, and a clinical exam was performed on each cat. A complete record of each cat was kept, including gender (male, female), age ( $<3$ or $\geq 3$ years), rearing condition (domestic or feral) and other demographic data. The ages of the feral cats were estimated according to the teeth and bones of the layer [23]. Approximately 3-5 $\mathrm{ml}$ blood samples were obtained and centrifuged at
A

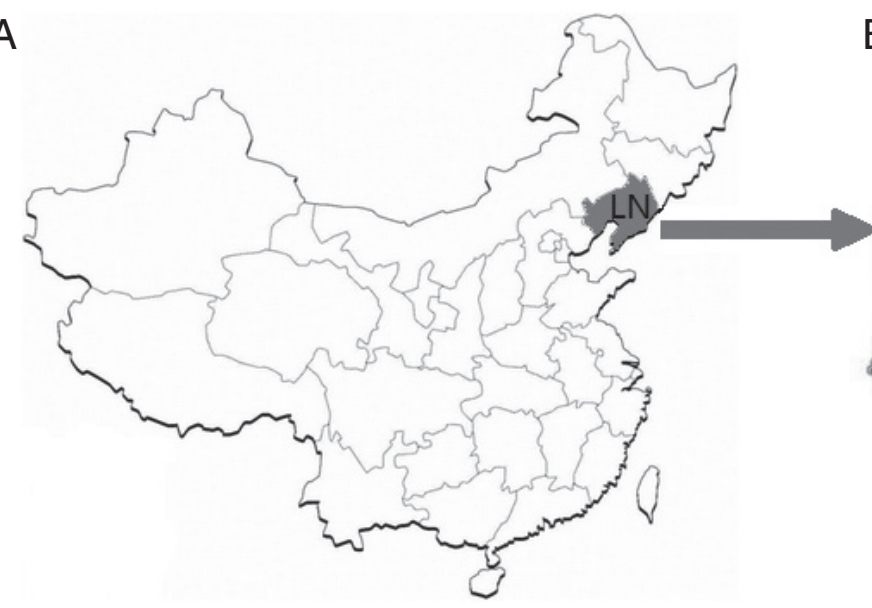

B

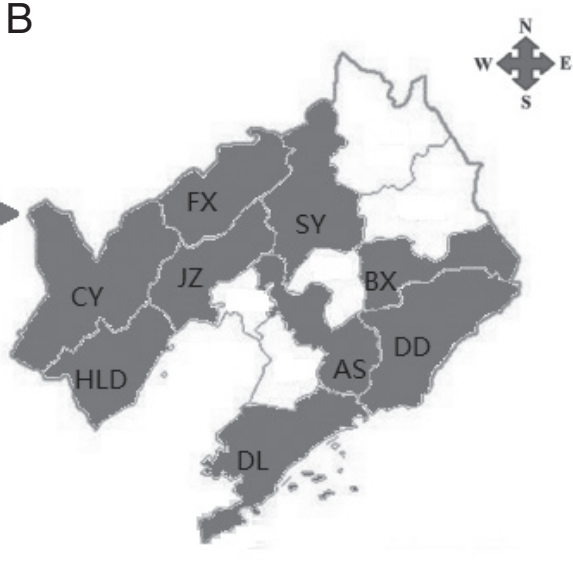

Fig. 1. Geographic distribution of the sampling site in Liaoning province, northeastern China. $(A)$ Liaoning province (LN) is located in the northeastern part of the mainland China. (B) Shadowed areas are sampling locations for the present study. SY, Shenyang; DL, Dalian; AS, Anshan; BX, Benxi; DD, Dandong; JZ, Jinzhou; HLD, Hulidao; CY, Chaoyang; FX, Fuxin. 
Table 1. The analysis of risk factors for $D$. immitis prevalence between domestic and feral cats in Liaoning province (northeastern China)

\begin{tabular}{|c|c|c|c|c|c|c|}
\hline Variable & Samples (n) & Positive (n) & Prevalence (\%) & OR & $95 \% \mathrm{Cl}$ & $P$-value \\
\hline \multicolumn{7}{|l|}{ Gender } \\
\hline Male & 319 & 15 & 4.7 & 1 & & NA \\
\hline Female & 332 & 14 & 4.2 & 1.12 & $0.53-2.35$ & $>0.05$ \\
\hline \multicolumn{7}{|l|}{ Age } \\
\hline$<3$ years $(0.5-3$ years $)$ & 363 & 6 & 1.7 & 1 & & NA \\
\hline$\geq 3$ years ( $3-12$ years) & 288 & 23 & 8 & 0.19 & $0.08-0.44$ & $<0.01$ \\
\hline \multicolumn{7}{|l|}{ Rearing condition } \\
\hline Domestic & 364 & 5 & 1.4 & 1 & & NA \\
\hline Feral & 287 & 24 & 8.4 & 0.15 & $0.06-0.36$ & $<0.01$ \\
\hline Total & 651 & 29 & 4.5 & & & \\
\hline
\end{tabular}

NA, not applicable.

$3,500 \mathrm{~g}$ for $10 \mathrm{~min}$, and sera were stored at $-20^{\circ} \mathrm{C}$ in airtight vials until tested. All samples were tested to detect $D$. immitis using a commercial antigen detection kit (SNAP Heartworm RT, IDEXX Laboratories, Westbrook, Maine, USA) according to the manufacturer's instructions. For the statistical analysis, the outcome variable was the prevalence of $D$. immitis, and the independent variables were gender (male, female), age ( $<3$ years, $\geq 3$ years), and rearing condition (domestic or feral). Seroprevalence with the odds ratio (OR), 95\% confidence intervals $(\mathrm{CI})$ and $P$-value $(P)$ were calculated.

The prevalence is $4.45 \%$, and $29 / 651$ tested samples were antigen positive samples. Since the presence of as few as 2 adult heartworms can cause cardiac enlargement and a severe acute respiratory syndrome in felines [24], an infected cat may have low production of heartworm antigens and antibodies. Therefore, the actual rate of infection may be higher than the test results indicated. The association of $D$. immitis prevalence and risk factors (gender, age and rearing condition) from positive cats were analyzed. There was no significant difference between the male and female cats $(15 / 14,4.7 \% / 4.2 \%, P>0.05$, OR $1.12,95 \% \mathrm{CI} 0.53-2.35)$. The prevalence of $D$. immitis was obviously difference between cats aged $\geq 3$ years and $<3$ years (23/6, 8.0\%/1.6\%, $P<0.01$, OR 0.19, 95\% CI 0.08-0.44), and the prevalence of $D$. immitis in feral cats was significantly higher than in domestic cats $(24 / 5,8.4 \% / 1.4 \%, P<0.01$, OR 0.15 , $95 \% \mathrm{CI} 0.06-0.36$ ). One possible reason is that domestic cats spent more time indoors as pets than feral cats, so feral cats could be exposed for a longer time to mosquitoes, with a consequently higher chance of being bitten by the mosquitoes $[25,26]$. The prevalence of $D$. immitis in different rearing conditions by age and gender group between domestic cats and feral cats is shown in Table 1. No significant difference in $D$. immitis prevalence was found in male and female cats $(4.7 \%$ vs $4.2 \%, P>0.05)$, which is in agreement with other studies, in stray and pet cats $(3.3 \%$ vs $2.7 \%, P>0.05)$ in northwestern China [21], in stray cats $(2.6 \%$ vs $2.6 \%, P>0.05)$ in south Korea [27], and in with or without outdoor access cats $(0.4 \%$ vs $0.4 \%$ ) in the United States and Canada [28] , but this result differs from Kramer and Genchi, in which the male cat prevalence was significantly higher than that in female cats $(19.0 \%$ vs $13.0 \%, P<0.01)$ [29]. Domestic cats aged $\geq 3$ years and $<3$ years showed no significant differences in prevalence $(P>$ $0.05)$. However, the prevalence of $D$. immitis in older feral cats was significantly higher compared to that in younger feral cats $(P<0.01)$. There is one existing report that older dogs were more likely to be infected with $D$. immitis [30], possibly because the older dogs were more likely to be exposed to mosquitoes for a longer time, with a consequently higher chance of being bitten, which might be the same reason for cats.

There are many surveys about the prevalence of $D$. immitis in dogs, but only few reports about the prevalence of $D$. immitis in cats in China and neighboring countries. The prevalence of $D$. immitis in stray and pet cats was 3.0\% (11/362) in Gansu province, northwestern China [21], and 1.9\% $(22 / 1,141)$ in Stray cats in Liaoning, Jilin, Heilongiiang, and Shandong province, eastern China [22]. The only report about the seroprevalence of D. immitis is $4.6 \%$ (34/746) in pet cats in Bangkok and vicinities, Thailand [31]. A survey of D. immitis infection among stray cats in Korea using nested PCR showed that 6.0\% (14/235) were positive for D. immitis [10], and 2.6\% (4/145) among stray cats in Gyunggi province in South Korea [27]. In Japan, a prevalence of D. immitis varying from 0.5 to $9.5 \%$ for stray cats and from 3.0 to $5.2 \%$ for house cats that has been examined since 1957 to 1998 [32]. However, no D. immitis was detected from 170 blood samples of domestic and stray cats in Malaysia [9]. There are increasing numbers of cats in 
China in the last 3 decades along with raising public health problems in view of cats can transmit a number of zoonotic pathogens, Epidemiological data of $D$. immitis is necessary to control and prevent feline dirofilariosis.

In conclusion, the study confirms the presence of $D$. immitis in domestic and feral cats and that the prevalence was significantly higher in feral cats, especially older feral cats. These results suggest that outdoor exposure time is one of the most important factors for $D$. immitis infection in cats. Therefore, the present study suggests that prophylaxis against the parasite is advisable to decrease the incidence of feline dirofilariosis in Liaoning Province, northeastern China.

\section{ACKNOWLEDGMENT}

This work was supported by the grant from National Key Technology R\&D program (no. 2015BAI07B02), and Natural Science Foundation of Liaoning Province (grant no. 201202082).

\section{CONFLICT OF INTEREST}

We have no conflict of interest related to this study.

\section{REFERENCES}

1. Genchi C, Rinaldi L, Mortarino M, Genchi M. Cringoli G. Climate and Dirofilaria infection in Europe. Vet Parasitol 2009; 163: 286-292.

2. Bowman DD, Atkins CE. Heartworm biology, treatment, and control. Vet Clin North Am Small Anim Pract 2009; 39: 1127-1158.

3. Genchi C, Mortarino M, Rinaldi L, Cringoli G, Traldi G, Genchi $\mathrm{M}$. Changing climate and changing vector-borne disease distribution, the example of Dirofilaria in Europe. Vet Parasitol 2011; 176: 295-299.

4. Simón F, Siles-Lucas M, Morchón R, González-Miguel J, Mellado I, Carretón E, Montoya-Alonso JA. Human and animal dirofilariasis: the emergence of a zoonotic mosaic. Clin Microbiol Rev 2012; 25: 507-544.

5. Miller MW. Feline dirofilariasis. Clin Tech Small Anim Pract 1998; 13: 99-108.

6. Simón F, Morchón R, González-Miguel J, Marcos-Atxutegi C, Siles-Lucas M. What is new about animal and human dirofilariosis? Trends Parasitol 2009; 25: 404-409.

7. Levy JK, Burling AN, Crandall MM, Tucker SJ, Wood EG, Foster JD. Seroprevalence of heartworm infection, risk factors for seropositivity, and frequency of prescribing heartworm preventives for cats in the United States and Canada. J Am Vet Med Assoc 2017; 250: 873-880.
8. Montoya-Alonso JA, Carretón E, Morchón R, Silveira-Viera L, Falcón Y, Simón F. The impact of the climate on the epidemiology of Dirofilaria immitis in the pet population of the Canary Islands. Vet Parasitol 2016; 216: 66-71.

9. Al-Abd NM, Nor ZM, Kassim M, Mansor M, Al-Adhroey AH, Ngui R, Sivanandam S. Prevalence of filarial parasites in domestic and stray cats in Selangor State, Malaysia. Asian Pac J Trop Med 2015; 8: 705-709.

10. Park HJ, Lee SE, Lee WJ, Oh JH, Maheswaran E, Seo KW, Song $\mathrm{KH}$. Prevalence of Dirofilaria immitis infection in stray cats by nested PCR in Korea. Korean J Parasitol 2014; 52: 691-694.

11. Vieira L, Silvestre-Ferreira AC, Fontes-Sousa AP, Balreira AC, Morchón R, Carretón E, Vilhena H, Simón F, Montoya-Alonso JA. Seroprevalence of heartworm (Dirofilaria immitis) in feline and canine hosts from central and northern Portugal. J Helminthol 2015; 89: 625-629.

12. Di Cesare A, Castagna G, Meloni S, Milillo P, Latrofa S, Otranto D, Traversa D. Canine and feline infections by Cardiopulmonary nematodes in central and southern Italy. Parasitol Res 2011; 109 (suppl): 87-96.

13. Liu C, Yang N, He J, Yang M, Sun M. Prevalence of Dirofilaria immitis in dogs in Shenyang, northeastern China. Korean J Parasitol 2013; 51: 375-377

14. Hou H, Shen G, Wu W, Gong P, Liu Q, You J, Cai Y, Li J, Zhang X. Prevalence of Dirofilaria immitis infection in dogs from Dandong, China. Vet Parasitol 2011; 183: 189-193.

15. Wang S, Zhang N, Zhang Z, Wang D, Yao Z, Zhang H, Ma J, Zheng B, Ren H, Liu S. Prevalence of Dirofilaria immitis infection in dogs in Henan province, central China. Parasite 2016; 23: 43.

16. He HQ, Yu SK, Lin Q, Ma QY, Cao GX, Tan J. Detection of microfilariae of Dirofilaria immitis in police dogs in Xian. Prog Vet Med 2005; 26: 114-115.

17. Sun M, Zhuo W, Guo S, Liao S, Shi D, Liu J, Cheng Z, Liu Y, Niu X, Wang S, Yang D. Serological survey of canine dirofilariosis in Chongqing, Kunming, Nanchang, Fuzhou, Guangzhou, Shenzhen, and Nanning in southern China. Vet Parasitol 2012; 18: 225-228.

18. Rao ZX, Zhang FN, Ye H. Survey of Dirofilaria immitis infection in domestic dog in Chongqing. Sichuan J Zool 1999; 2.

19. Xia Z, Yu D, Mao J, Zhang Z, Yu J. The occurrence of Dirofilaria immitis, Borrelia burgdorferi, Ehrlichia canis and Anaplasma phagocytophium in dogs in China. J Helminthol 2012; 86: 185-189.

20. Fan CK, Su KE, Lin YH, Liao CW, Du WY, Chiou HY. Seroepidemiologic survey of Dirofilaria immitis infection among domestic dogs in Taipei city and mountain aboriginal districts in Taiwan (1998-1999). Vet Parasitol 2001; 102: 113-120.

21. Cong W, Meng QF, Blaga R, Villena I, Zhu XQ, Qian AD. Toxoplasma gondii, Dirofilaria immitis, feline immunodeficiency virus (FIV), and feline leukemia virus (FeLV) infections in stray and pet cats (Felis catus) in northwest China: co-infections and risk factors. Parasitol Res 2016; 115: 217-223.

22. Kang YH, Cong W, Qin SY, Shan XF, Gao YH, Wang CF, Qian AD. First report of Toxoplasma gondii, Dirofilaria immitis, and 
Chlamydia felis infection in stray and companion cats in northeastern and eastern China. Vector Borne Zoonotic Dis 2016; 16: 654-658.

23. Legendre L. The Veterinarian's companion for common dental procedures. Can Vet J 2001; 42: 470.

24. Borgarelli M, Venco L, Piga PM, Bonino F, Ryan WG. Surgical removal of heartworms from the right atrium of a cat. J Am Vet Med Assoc 1997; 211: 68-69.

25. Montoya JA, Morales M, Ferrer O, Molina JM, Corbera JA. The prevalence of Dirofilaria immitis in Gran Canaria, Canary Islands, Spain (1994-1996). Vet Parasitol 1998; 75: 221-226.

26. Montenegro VM, Bonilla MC, Kaminsky D, Romero-Zúñiga JJ, Siebert S, Krämer F. Serological detection of antibodies to Anaplasma spp., Borrelia burgdorferi sensu lato and Ehrlichia canis and of Dirofilaria immitis antigen in dogs from Costa Rica. Vet Parasitol 2017; 236: 97-107.

27. Liu J, Song KH, Lee SE, Lee JY, Lee JI, Hayasaki M, You MJ, Kim DH. Serological and molecular survey of Dirofilaria immitis infection in stray cats in Gyunggi province, South Korea. Vet Parasitol 2005; 130: 125-129.

28. Levy JK, Burling AN, Crandall MM, Tucker SJ, Wood EG, Foster
JD. Seroprevalence of heartworm infection, risk factors for seropositivity, and frequency of prescribing heartworm preventives for cats in the United States and Canada. J Am Vet Med Assoc 2017; 250: 873-880.

29. Kramer L, Genchi C. Feline heartworm infection: serological survey of asymptomatic cats living in northern Italy. Vet Parasitol 2002; 104: 43-50.

30. Yuasa Y, Hsu TH, Chou CC, Huang CC, Huang WC, Chang CC. The comparison of spatial variation and risk factors between mosquito-borne and tick-borne diseases: Seroepidemiology of Ehrlichia canis, Anaplasma species, and Dirofilaria immitis in dogs. Comp Immunol Microbiol Infect Dis 2012; 35: 599-606.

31. Sukhumavasi W, Bellosa ML, Lucio-Forster A, Liotta JL, Lee AC, Pornmingmas P, Chungpivat S, Mohammed HO, Lorentzen L, Dubey JP, Bowman DD. Serological survey of Toxoplasma gondii, Dirofilaria immitis, Feline Immunodeficiency Virus (FIV) and Feline Leukemia Virus (FeLV) infections in pet cats in Bangkok and vicinities, Thailand. Vet Parasitol 2012; 188: 25-30.

32. Roncalli RA, Yamane Y, Nagata T. Prevalence of Dirofilaria immitis in cats in Japan. Vet Parasitol 1998; 75: 81-89. 
